\title{
Evaluation of the American Heart Association 2015 revised Jones criteria versus existing guidelines
}

\author{
Dinesh Kumar, ${ }^{1}$ Euden Bhutia, ${ }^{1}$ Pradeep Kumar, ${ }^{2}$ Binoy Shankar, ${ }^{1}$ Atul Juneja, ${ }^{3}$ \\ Sudha Chandelia ${ }^{1}$
}

${ }^{1}$ Department of Paediatrics, PGIMER and associated Dr Ram Manohar Lohia Hospital, New Delhi, India ${ }^{2}$ Department of Pediatrics and Neonatology, Rani Children's Hospital, Ranchi, India ${ }^{3}$ Department of Biostatistics, National Institute of Medical Statistics (ICMR), Delhi, India

Correspondence to Dr Dinesh Kumar, Division of Paediatric Cardiology, Department of Paediatrics, PGIMER and associated Dr Ram Manohar Lohia Hospital, Room no 238, OPD Block, New Delhi 110001, India; dineshkumar169@yahoo.co.in

Received 20 November 2015 Revised 12 January 2016 Accepted 4 February 2016

\section{CrossMark}

To cite: Kumar D, Bhutia $E$, Kumar $\mathrm{P}$, et al. Heart Asia 2016:8:30-35.

doi:10.1136/heartasia-2015010709

\begin{abstract}
Objectives To compare the diagnostic yield of acute rheumatic fever (ARF) by the American Heart Association/ American College of Cardiology (AHA/ACC) 2015 revised Jones criteria with the WHO 2004 and Australian guidelines 2012.
\end{abstract}

Methods Retrospective observational study in 93 cases of suspected ARF admitted to the Division of Paediatric Cardiology between January 2012 and December 2014. WHO 2004, Australian guidelines and AHA/ACC 2015 Jones criteria were applied to assess definite and probable ARF.

Results Of the 93 cases, 50 were diagnosed as the first episode of ARF and 43 as a recurrence of the condition. Subclinical carditis was a predominant presentation $(38 \%)$ in the first episode group $(p<0.01)$ whereas in the recurrence group carditis $(88 \%)$ was the main presentation $(p<0.01)$. Among the joint manifestations, the majority of patients in both the first episode group and the recurrence group presented with arthralgia. Of all the patients with suspected ARF (50), $34 \%$ of cases did not fulfil the standard Jones criteria 2004; however, $86 \%$ qualified as having ARF on applying the Australian and AHA/ACC 2015 criteria. Surprisingly in the recurrence group only $67 \%$ of the patients fulfilled AHA/ACC 2015 despite the modifications incorporated beyond WHO 2004; however, all the patients fulfilled the Australian guidelines either as definite $(88.4 \%)$ or probable $(11.6 \%)$. Inclusion of subclinical carditis, polyarthralgia and monoarthritis as major criteria influenced the diagnosis to definite ARF in $20 \%, 10 \%$ and $4 \%$ of patients, respectively.

Conclusions The clinical manifestations of ARF, comprising subclinical carditis and arthralgia, are possibly milder in the Indian population; hence, inclusion of subclinical carditis, polyarthralgia and monoarthritis as major criteria in the newer guidelines has improved the diagnostic yield of ARF. In the absence of a gold standard for the diagnosis of ARF, it is not possible to comment on sensitivity and specificity.

\section{INTRODUCTION}

The global distribution of acute rheumatic fever (ARF)/rheumatic heart disease (RHD) is essentially disproportionate. The incidence of ARF is high in low-income countries, in certain geographic regions, and among certain socioeconomic groups, whereas in other regions the disease has become rare. Also, the disease has become less severe, and certain manifestations that were common in the past (severe carditis and subcutaneous nodules) are now rare. ${ }^{1}$
The Jones criteria represent the clinical standard to establish the diagnosis and have undergone several revisions over the years due to the declining incidence of ARF in the West. These revisions increased the specificity but at the cost of sensitivity, thereby undermining the diagnostic abilities of physicians in low-income nations where the disease is endemic. Thus, a single set of diagnostic criteria may no longer be appropriate for all population groups which may result in overdiagnosis in low incidence populations and underdiagnosis in highrisk populations. Recurrences can be prevented by secondary penicillin prophylaxis thereby underlining the need to establish a correct diagnosis.

The idea of re-evaluating of the diagnostic criteria, particularly in high-prevalence areas, gained momentum with the introduction of separate diagnostic guidelines by Australia and New Zealand. ${ }^{2} 3$ These changes were prompted by new findings of the disease following the application of echocardiographic techniques such as quantitative Doppler and colour flow mapping, underscoring the need to diagnose carditis even in the absence of overt clinical findings ('subclinical carditis'). ${ }^{4-6}$ Also, publications from selective high-risk populations have indicted monoarticular arthritis and polyarthralgia as the major manifestation of arthritis.

Recently, the American Heart Association/ American College of Cardiology (AHA/ACC) (2015) has come up with a revision of the Jones criteria which has incorporated major modifications for highprevalence areas to improve the diagnostic yield. ${ }^{1}$

ARF and RHD occur at high rates in the Indian subcontinent, predominantly affect children, adolescents and young adults and are important causes of premature mortality. Until recently we have followed the Jones criteria (WHO 2004) ${ }^{89}$ and have possibly missed a large number of patients with ARF. Hence, it was planned to study the clinical characteristics of patients with first episode of ARF and recurrence visiting our tertiary care centre and to evaluate the appropriateness and strength of the new variable clinical manifestations of ARF included in AHA/ACC 2015 guidelines towards modifying the classification of suspected cases. We compared the diagnostic yield of ARF by the AHA/ ACC 2015 guidelines over WHO 2004 and also with the Australian guidelines 2012.

\section{PATIENTS AND METHODS}

A retrospective observational study was conducted. The hospital records for all children with suspected first episode of ARF and recurrence in the paediatric age group (5-18 years) admitted between January 2012 and December 2014 to the Division 
of Paediatric Cardiology, PGIMER, and associated Dr Ram Manohar Lohia Hospital New Delhi were reviewed. Those fulfilling either Jones criteria WHO 2004 or Australian guidelines 2012 were identified and included in the study. Files were reviewed meticulously for demographic data, clinical findings and laboratory reports on admission and during the hospital stay and those with incomplete information were removed. Children with congenital heart disease and other acquired heart diseases like cardiomyopathies, Kawasaki disease, juvenile rheumatoid arthritis and other connective tissue disorders were excluded.

Carditis was diagnosed on account of any of the following: a precordial murmur, pericardial rub or effusion, cardiac failure and radiographic cardiomegaly. ${ }^{29}$ In people with known RHD, carditis consisted of a new, worsened, or changed murmur or cardiac failure in the presence of other evidence of active rheumatic inflammation.

Arthritis was defined as inflammation (swollen, red and warm) and restriction of movement of joints; monoarthritis was defined as involvement of a single joint, whereas polyarthritis meant involvement of several joints. Arthralgia was defined as involvement of the joint without swelling. ${ }^{2}{ }^{9}$

Sydenham's chorea was diagnosed in the presence of semipurposeful abnormal movement of extremities. Erythema marginatum was defined as evanescent erythematous macular rash with serpiginous border and central clearing. Subcutaneous nodules were identified as almond-shaped, non-tender nodules on bony prominence. ${ }^{29}$

Elevated erythrocyte sedimentation rate (ESR) and $\mathrm{C}$ reactive protein (CRP) were considered as $>30 \mathrm{~mm} / \mathrm{h}$ and $>30 \mathrm{mg} / \mathrm{L}$, respectively. ${ }^{10}{ }^{11}$ Age wise upper limit of normal for anti streptolysine O (ASO) was defined as $120 \mathrm{IU} / \mathrm{mL}$ for children aged 4-5 years, $480 \mathrm{IU} / \mathrm{mL}$ for $6-9$ years, and $320 \mathrm{IU} / \mathrm{mL}$ for those aged over 10 years. ${ }^{12}$ Similarly age wise upper limit of normal for anti-DNase B was defined as $100 \mathrm{IU} / \mathrm{mL}$ for children aged 4-5 years, $400 \mathrm{IU} / \mathrm{mL}$ for $6-9$ years and $380 \mathrm{IU} / \mathrm{mL}$ for those aged $>10$ years. ${ }^{12}$

Echocardiograms were reviewed for valvular lesions particularly to determine whether pathological regurgitation (minor degrees of mitral or aortic valve regurgitation with colour Doppler manifestations) was present as described by the Australian guidelines 2012 and ACC/AHA 2015. Subclinical carditis was considered in those patients with no audible murmur but echocardiographic evidence of valvular regurgitation.

The patients were analysed with respect to first episode of ARF and recurrence according to the Jones criteria WHO 2004, Australian guidelines 2012 and AHA/ACC 2015 (table 1).

Statistical analysis was conducted using SPSS V.17.0 (Chicago, Illinois, USA). Results are expressed as mean $\pm \mathrm{SD}$, numbers and percentages. Categorical variables were analysed using either the $\chi^{2}$ or Fisher's exact test. For all statistical tests, a value of $\mathrm{p}<0.05$ was considered significant. Clearance was obtained from institutional ethical board.

\section{RESULTS}

Of the 93 cases of suspected ARF and recurrence, 50 were diagnosed as first episode of ARF and 43 as recurrence. The overall male:female ratio was $1.6: 1$ with a mean age of 11.3 years (range: 6-18). There was no difference between the mean age at presentation and the male:female ratio between the two groups. The clinical profile of each group is given in table 2 .

Clinical carditis was the hallmark lesion $(88 \%)$ in the recurrence group of patients, whereas in the first episode patients subclinical carditis was a significant presenting finding (38\%, $\mathrm{n}=19$, table 2). Six (6.4\%) patients had no evidence of cardiac involvement even on echocardiography; four of them were from the first episode of ARF group.

Joint symptoms were present in the majority of patients (74\%) with first episode of ARF while it was less common $(37 \%)$ in patients with recurrence. Arthralgia $(81 \%, n=13)$ was the characteristic form of joint involvement while arthritis $(19 \%, n=3)$ occurred in a minority of patients with recurrence unlike in the cases with first episode of ARF where arthralgia $(40 \%, n=20)$ and arthritis $(34=, n=17)$ were almost equal in their distribution.

Chorea was present in 16\% $(n=8)$ of the cases and all of them had subclinical carditis except one. Joint involvement was uncommon (arthralgia $n=2$, arthritis $n=1$ ). Two patients $(4.7 \%)$ presented with recurrence of chorea. They had subclinical carditis and no joint symptoms.

None of the patients had subcutaneous nodules or erythema marginatum. The median value of ESR and CRP, ASO and anti-DNase B was similar in both groups (table 3). In the first episode of ARF, ASO was positive in $60 \%$ of patients, anti-DNase B in $80 \%$ while ASO and anti-DNase B combined were positive in $92 \%$ of cases. Similar values were found in the recurrence cases.

On echocardiography, mitral regurgitation was the most common lesion followed by aortic regurgitation in both the groups. Isolated mitral regurgitation was the predominant single valvular lesion while mitral and aortic regurgitation together constituted the most common combination lesion. Combination valvular lesions were more common in the recurrence group than in the first episode ARF group. Mitral regurgitation was usually severe in the recurrence group while it was mild in the first episode of ARF group (table 4).

In the first episode of ARF group using WHO 2004 and AHA/ACC 2015 criteria, 66\% and 86\% of cases respectively, qualified as ARF. Using Australian guidelines, definite ARF was identified in $86 \%$ of the patients while seven (14\%) patients were labelled as probable ARF (table 5).

In the recurrence group, $67 \%$ of cases fulfilled WHO 2004 but there was no improvement in the yield with the new AHA/ ACC 2015 criterion. All patients fulfilled the Australian guidelines either as definite $88.4 \%$ or probable $11.6 \%$ (5).

\section{Impact of subclinical carditis on the diagnosis of rheumatic fever}

In the suspected first episode of ARF group, the incidence of subclinical carditis was 38\% $(n=19)$. However, in nine of these patients other major (chorea 7, polyarthritis 2 ) and/or minor criteria envisaged in WHO 2004 were present, completing the diagnosis of ARF, and the presence of subclinical carditis only reinforced the diagnosis.

However, by inclusion of subclinical carditis as a major criteria it influenced the diagnosis in $10(20 \%)$ suspected cases who had either only one single major (polyarthralgia (five cases), polyarthritis (two cases) and monoarthritis (one case)) or insufficient minor criteria to be labelled as ARF (table 6).

In the recurrence group subclinical carditis $(n=3)$ did not increase the number of cases with recurrence activity as these patients already met the WHO 2004 criteria for diagnosing ARF.

Impact of polyarthralgia and monoarthritis on the diagnosis of rheumatic fever

In the first episode of ARF, inclusion of monoarthritis as a major criteria enhanced the diagnosis of ARF in two (4\%) cases 
Table 1 Criteria used for defining ARF

\begin{tabular}{|c|c|c|c|}
\hline Criteria & WHO 2004 & $\begin{array}{l}\text { Australian guidelines } \\
\text { For high-risk population }\end{array}$ & $\begin{array}{l}\text { AHA/ACC } 2015 \\
\text { For high-risk population }\end{array}$ \\
\hline Major manifestations & $\begin{array}{l}\text { Carditis } \\
\text { - Polyarthritis } \\
\text { - Chorea } \\
\text { - Erythema marginatum } \\
\text { - Subcutaneous nodules }\end{array}$ & $\begin{array}{l}\text { Carditis (including subclinical carditis) } \\
\text { Or Polyarthritis } \\
\text { Or } \\
\text { Or Aseptic monoarthritis } \\
\text { Or Polyarthralgia } \\
\text { Chorea } \\
\text { - Erythema marginatum } \\
\text { - Subcutaneous nodules }\end{array}$ & $\begin{array}{l}\text { - Carditis (clinical and/or subclinical) } \\
\text { - Polyarthritis } \\
\text { Or } \\
\text { Or Monoarthritis } \\
\text { Or } \\
\text { - Polyarthralgia } \\
\text { - Chorea } \\
\text { - Erythema marginatum } \\
\text { - Subcutaneous nodules }\end{array}$ \\
\hline Minor manifestations & $\begin{array}{l}\text { - Fever } \\
\text { Polyarthralgia } \\
\text { - Elevated acute phase reactants } \\
\text { (ESR or raised leucocyte count) } \\
\text { - Prolonged PR interval }\end{array}$ & $\begin{array}{l}\text { Fever } \\
\text { ESR } \geq 30 \mathrm{~mm} / \mathrm{h} \text { or CRP } \geq 30 \mathrm{mg} / \mathrm{L} \\
\text { Prolonged PR interval } \\
\text { - Monoarthralgia }\end{array}$ & $\begin{array}{l}\text { Fever } \\
\text { ESR } \geq 30 \mathrm{~mm} / \mathrm{h} \text { or CRP } \geq 30 \mathrm{mg} / \mathrm{L} \\
\text { Prolonged PR interval } \\
\text { Monoarthralgia }\end{array}$ \\
\hline $\begin{array}{l}\text { Essential criteria } \\
\text { (preceding GAS } \\
\text { infection) }\end{array}$ & $\begin{array}{l}\text { - Rising ASO or other streptococcal } \\
\text { antibody } \\
\text { - Positive throat infection } \\
\text { - Rapid antigen test }\end{array}$ & $\begin{array}{l}\text { Rising ASO or other streptococcal antibody } \\
\text { Positive throat infection } \\
\text { - Rapid antigen test }\end{array}$ & $\begin{array}{l}\text { - Rising ASO or other streptococcal } \\
\text { antibody } \\
\text { - Positive throat infection } \\
\text { - Rapid antigen test }\end{array}$ \\
\hline Initial ARF & $\begin{array}{l}\text { Two major } \\
\text { Or } \\
\text { One major and two minor } \\
\text { Plus } \\
\text { Evidence of preceding GAS infection }\end{array}$ & $\begin{array}{l}\text { Definite } \\
\text { Two major } \\
\text { Or } \\
\text { One major and two minor } \\
\text { Plus } \\
\text { Evidence of preceding GAS infection } \\
\text { Falls short by either one major or one minor or } \\
\text { absence of evidence of GAS infection but } \\
\text { where } \\
\text { ARF is considered most likely }\end{array}$ & $\begin{array}{l}\text { Two major } \\
\text { Or } \\
\text { One major and two minor } \\
\text { Plus } \\
\text { Evidence of preceding GAS infection } \\
\text { Possible }\end{array}$ \\
\hline Recurrence & $\begin{array}{l}\text { Without established RHD } \\
\text { Two major } \\
\text { Or } \\
\text { One major and two minor } \\
\text { Plus } \\
\text { Evidence of preceding GAS infection } \\
\text { With established RHD } \\
\text { Two minor } \\
\text { Plus } \\
\text { Evidence of preceding GAS infection }\end{array}$ & $\begin{array}{l}\text { Two major } \\
\text { Or } \\
\text { One major and one minor } \\
\text { Or } \\
\text { Three minor } \\
\text { Plus } \\
\text { Evidence of preceding GAS infection }\end{array}$ & $\begin{array}{l}\text { Two major } \\
\text { Or } \\
\text { One major and two minor } \\
\text { Or } \\
\text { Three minor } \\
\text { Plus } \\
\text { Evidence of preceding GAS infection }\end{array}$ \\
\hline
\end{tabular}

ARF, acute rheumatic fever; ASO, anti streptolysine $0 ; C R P, C$ reactive protein; ESR, erythrocyte sedimentation rate; GAS, group A streptococci; PR, pulmonary regurgitation; RHD, rheumatic heart disease.

only as the remaining three cases already fulfilled WHO 2004 guidelines on account of the presence of criteria as envisaged for diagnosing ARF (table 6).

In our study, 32\% $(n=16)$ of patients presented with polyarthralgia as a minor manifestation with first episode of ARF and $18 \%(n=9)$ of patients could make it to the final diagnosis of ARF using WHO 2004 criteria. However, with the ACC/AHA 2015 and Australian guidelines 28\% $(n=14)$ of cases could qualify as ARF on account of the upgrading of polyarthralgia to a major criteria thus yielding $10 \%$ more cases.

However, this intervention did not increase the tally of patients being diagnosed with 'activity' in the recurrence group.

\section{DISCUSSION}

Clinical manifestations of rheumatic fever in the Indian subcontinent may be different from the West and other high-prevalence areas of the world. First, the joint manifestations were markedly less common (overall 59\%, first episode ARF 72\% and recurrence $37 \%$ ) in our patients as compared with studies from aboriginal population of Australia and New Zealand (first episode ARF: $91 \%$ and $89 \%$, respectively). ${ }^{7} 13$
Second, arthralgia was the dominant joint manifestation in our patients (overall 35\%, first episode $40 \%$ and recurrence $30 \%$ ) in comparison to arthritis which was present in a smaller proportion of cases, markedly so in the recurrence group (overall 21\%, first episode 34\% and recurrence 19\%). This is in contrast to the studies Carapetis and Currie ${ }^{7}$ from Australia and Wilson et $a l^{13}$ from New Zealand where arthritis was the predominant manifestation than arthralgia (arthritis: arthralgia $78 \% / 28 \%$ and $62 \% / 27 \%$, respectively). However, Carapetis and Currie $^{7}$ also observed that arthralgia was more common in recurrence (46\%) than first episode (28\%).

Third, in the current study arthritis and polyarthritis were diagnosed more commonly in first episodes (34\% and 24\%, respectively) than recurrences (6.9\% and $4 \%$, respectively), but the frequency of these manifestations were quite lower than that reported by Carapetis and Currie $^{7}$ (first episode: arthritis $78 \%$ and polyarthritis 64\%; recurrence: $63 \%$ and $43 \%$, respectively).

The presentation and spectrum of disease had subtle variation between the first episode and recurrence of ARF. Subclinical carditis was a predominant presentation in the first episode 
Table 2 Clinical characteristics of patients with first episode ARF and recurrence

\begin{tabular}{|c|c|c|c|}
\hline & $\begin{array}{l}\text { First episode ARF } \\
\mathrm{n}(\%), \mathrm{n} \pm \text { SD }\end{array}$ & $\begin{array}{l}\text { Recurrence } \\
n(\%), n \pm S D\end{array}$ & p Value \\
\hline Age & $10.90 \pm 2.32$ & $11.79 \pm 2.47$ & \\
\hline \multicolumn{4}{|l|}{ Sex } \\
\hline Female & $16(32 \%)$ & 19 (44.2\%) & 0.22 \\
\hline Male & $34(68 \%)$ & $24(55.8 \%)$ & \\
\hline \multicolumn{4}{|l|}{ Religion } \\
\hline Hindu & $41(82 \%)$ & 38 (88.4\%) & 0.39 \\
\hline Muslim & $9(18 \%)$ & $5(11.6 \%)$ & \\
\hline Clinical carditis & 27 (54\%) & $38(88 \%)$ & $<0.01$ \\
\hline Subclinical carditis & $19(38 \%)$ & $3(7 \%)$ & $<0.01$ \\
\hline Chorea & $8(16 \%)$ & $2(4.7 \%)$ & 0.07 \\
\hline Arthritis & $17(34 \%)$ & $3(6.9 \%)$ & 0.01 \\
\hline Monoarthritis & $5(29 \%)$ & $1(34 \%)$ & 0.14 \\
\hline Polyarthritis & $12(70 \%)$ & $2(66 \%)$ & $<0.01$ \\
\hline Subcutaneous nodules & 0 & 0 & \\
\hline Erythema marginatum & 0 & 0 & \\
\hline Fever & $34(68 \%)$ & $28(65 \%)$ & 0.76 \\
\hline Arthralgia & $20(40 \%)$ & $13(30.2 \%)$ & 0.32 \\
\hline Mono arthralgia & $4(20 \%)$ & $3(23 \%)$ & 0.852 \\
\hline Polyarthralgia & $16(80 \%)$ & $10(77 \%)$ & 0.35 \\
\hline High ESR & $34(68 \%)$ & $33(76.7 \%)$ & 0.35 \\
\hline High CRP & $16(32 \%)$ & $24(55.8 \%)$ & 0.02 \\
\hline ASO titre positive & $30(60 \%)$ & $21(48.8 \%)$ & 0.28 \\
\hline Anti-DNase B positive & $40(80 \%)$ & 35 (81.4\%) & 0.86 \\
\hline
\end{tabular}

ARF, acute rheumatic fever; ASO, anti streptolysine $0 ;$ CRP, C reactive protein; ESR, erythrocyte sedimentation rate.

(38\%) as opposed to carditis (88\%) in recurrence cases. Similarly, joint manifestations were more common in the first episode $(74 \%)$ than in recurrence (37\%) cases and so was arthritis and polyarthritis. By contrast arthralgia was the most common joint manifestation in recurrence $(81 \%)$ cases.

The modified WHO 2004 guidelines discussed subclinical carditis in ARF but did not include it as a major manifestation in the Jones criteria. Subclinical carditis has been reported in $30 \%$ of ARF cases ${ }^{13}$ from high-prevalence areas of the Pacific region which are less than that in our study (37\%). In a recent meta-analysis of subclinical carditis in ARF, the prevalence ranged from $0 \%$ to $53 \%$ (weighted pooled prevalence $18.1 \%){ }^{1}{ }^{14}$

The broadened all-inclusive definition of carditis (including subclinical cases) in the present study resulted in an overall increase in the number of patients with carditis from 54\% (WHO 2004) to $92 \%$ in cases of first episode of ARF. Clinical characterisation of 'carditis' actually resulted in underdiagnosis of ARF. Inclusion of subclinical carditis as a major criteria qualified $20 \%$ more cases as definite ARF which is slightly more than

Table 3 Mean (IQR) of laboratory parameters

\begin{tabular}{lc}
\hline & Mean (IQR) \\
\hline ESR & $44.4(20-57.25)$ \\
CRP & $13.50(9.55-32.50)$ \\
ASO & $418.50(189.75-611.75)$ \\
Anti-DNase B & $667(389.25-1050)$ \\
\hline ASO, anti streptolysine 0; CRP, C reactive protein; ESR, erythrocyte sedimentation \\
rate.
\end{tabular}

Table 4 Valvular involvement in patients with first episode ARF and recurrence

\begin{tabular}{|c|c|c|c|}
\hline Valvular involvement & $\begin{array}{l}\text { First episode ARF } \\
\text { (n) }\end{array}$ & $\begin{array}{l}\text { Recurrence } \\
\text { (n) }\end{array}$ & $\mathrm{p}$ Value \\
\hline \multicolumn{4}{|l|}{ MR } \\
\hline Mild & 20 & 4 & $<0.001$ \\
\hline Moderate & 9 & 7 & 0.83 \\
\hline Severe & 16 & 26 & 0.005 \\
\hline \multicolumn{4}{|l|}{ AR } \\
\hline Mild & 13 & 14 & 0.48 \\
\hline Moderate & 7 & 4 & 0.48 \\
\hline Severe & 5 & 6 & 0.56 \\
\hline \multicolumn{4}{|l|}{ TR } \\
\hline Mild & 8 & 14 & 0.06 \\
\hline Moderate & 1 & 6 & 0.03 \\
\hline Severe & 3 & 4 & 0.55 \\
\hline \multicolumn{4}{|l|}{ PR } \\
\hline Mild & 2 & 5 & \\
\hline Moderate & 0 & 3 & 0.16 \\
\hline Severe & 0 & 0 & 0.09 \\
\hline \multicolumn{4}{|l|}{ MS } \\
\hline Mild & 0 & 2 & 0.24 \\
\hline Moderate & 0 & 2 & 0.24 \\
\hline Severe & 0 & 8 & 0.001 \\
\hline \multicolumn{4}{|l|}{ AS } \\
\hline Mild & 0 & 0 & 0.46 \\
\hline Moderate & 0 & 1 & 0.24 \\
\hline Severe & 0 & 2 & \\
\hline No lesion & 4 & 0 & 0.07 \\
\hline Only MR & 19 & 8 & 0.04 \\
\hline$M R+T R$ & 3 & 4 & 0.55 \\
\hline$M R+A R$ & 14 & 5 & 0.05 \\
\hline$M R+A R+T R$ & 7 & 8 & 0.55 \\
\hline$M R+A R+T R+P R$ & 2 & 1 & 0.55 \\
\hline Only MS & 0 & 1 & 0.46 \\
\hline $\mathrm{MS}+\mathrm{MR}$ & 0 & 2 & 0.24 \\
\hline$M S+M R+A R+T R$ & 0 & 3 & 0.09 \\
\hline$M S+A R+A S+T R+P R$ & 0 & 1 & 0.46 \\
\hline Only AR & 1 & 0 & 0.54 \\
\hline$A R+M R+T R+A S$ & 0 & 1 & 0.46 \\
\hline$A R+A S+M R+T R+P R$ & 0 & 1 & 0.46 \\
\hline
\end{tabular}

$A R$, aortic regurgitation; $A R F$, acute rheumatic fever; $A S$, aortic stenosis; $M R$, mitral regurgitation; MS, mitral stenosis; PR, pulmonary regurgitation; TR, tricuspid regurgitation.

that in the studies by Wilson $e$ e $\mathrm{ll}^{13}(8 \%)$ and Cann $e$ et $a l^{5}(9 \%)$ from Australia and New Zealand, respectively. This is the first study from India to show the influence of subclinical carditis as a major criterion for the diagnosis of ARF.

In the current AHA/ACC guidelines the ambit of arthritis has been increased by including polyarthralgia and monoarthritis as major criteria and monoarthralgia as a minor criterion for highprevalence areas.

Several studies from Northern India reported much higher percentages of arthritis $(52 \%-87 \%)^{10} 11$ 15 than in our study. Indian literature is replete with arthralgia as a predominant manifestation of rheumatic fever (33\%-90\%). ${ }^{15-17}$ Roy $^{16}$ even suggested in 1960 that arthralgia be included as a major manifestation in the Jones criteria. Until 1956, it was considered to be a major criterion for the diagnosis of ARF. We also found that upgrading of polyarthralgia to a major criterion influenced the diagnosis in $10 \%$ of cases. 
Table 5 Comparative statement of ARF diagnosis (first episode and recurrence) WHO 2004 against newer guidelines

\begin{tabular}{llll}
\hline $\begin{array}{l}\text { Total suspected cases } \\
(\mathbf{n}=93)\end{array}$ & $\begin{array}{l}\text { WHO } \\
2004 \\
\%(\mathbf{n})\end{array}$ & $\begin{array}{l}\text { Australian } \\
\text { guidelines } \\
\%(\mathbf{n})\end{array}$ & $\begin{array}{l}\text { AHA/ACC } \\
2015 \\
\%(\mathbf{n})\end{array}$ \\
\hline First episode ARF (50) & $66(33)$ & $\begin{array}{l}\text { Definite: } 86(43) \\
\text { Probable: } 14(7)\end{array}$ & $86(43)$ \\
Recurrence (43) & $67(29)$ & $\begin{array}{l}\text { Definite: } 88.4(38) \\
\text { Probable: } 11.6(5)\end{array}$ & $67(29)$ \\
\hline
\end{tabular}

ARF, acute rheumatic fever.

We found monoarthritis in $10 \%(n=5)$ of the patients with suspected first episode of ARF which is similar to studies from India $(4 \%-13 \%)^{10}{ }^{11}$ and several high-risk indigenous populations $(16 \%-18 \%) .^{2}$ Generally monoarthritis without nonsteroidal anti-inflammatory drug (NSAID) use has rarely been observed; in Australian guidelines it is now accepted as a major criterion. In India, over the counter NSAIDs are freely available, and is a cause of concern for both underdiagnosis as well as complicating the diagnosis of ARF. Monoarthritis as a major criterion influenced the diagnosis of definite ARF in a small number of our patients (4\%) similar to that reported by Wilson et $a l^{13}(8 \%)$ and Cann et $a l^{5}(12 \%)$ thereby justifying its inclusion as a major criterion.

Anti-DNase B was positive in $80 \%$ of cases in both the groups whereas ASO was positive in only $60 \%$ and $48.8 \%$ of cases of first episode and recurrence, respectively. The immune response to group A streptococci skin infection in the form of antistreptolysin $\mathrm{O}$ is weak compared with throat infection, whereas the anti-DNase B response after infection at either site is strong. ${ }^{18}$ It raises questions that possibly the throat infection in our study produced a poor ASO response or else it was the pyoderma which caused ARF. ${ }^{19}$ This needs to be clarified, as it has important implications for primary prevention in lowincome/middle-income countries.

With the AHA/ACC 2015 guidelines, 86\% of cases qualified as having ARF which is higher than that obtained using the WHO 2004 criteria (66\%). Similar results were obtained with the Australian guidelines (ARF (definite): 86\%). Cann et $a l^{5}$ found $20 \%$ more cases being diagnosed as definite ARF on modifying the 1992 AHA/ACC Jones criteria (including

Table 6 Comparison of Australian and AHA 2015 guidelines with WHO 2004 guidelines: major criteria for ARF

\begin{tabular}{lll}
\hline & $\begin{array}{l}\text { Australian and AHA 2015 } \\
\text { guidelines } \\
\mathbf{n}(\%)\end{array}$ & $\begin{array}{l}\text { WHO 2004 } \\
\mathbf{n}(\%)\end{array}$ \\
\hline $\begin{array}{l}\text { Variables } \\
\text { symptoms }\end{array}$ & $33(66)$ & $28(56)$ \\
Monoarthritis & $5(8)^{*}$ & 0 by definition \\
Polyarthralgia & $16(32) \dagger$ & $\begin{array}{l}16(32) \text { minor } \\
\text { criteria } \\
12(24)\end{array}$ \\
Polyarthritis & $12(24)$ & $\begin{array}{l}27(54) \\
27(54)\end{array}$ \\
Total carditis & $46(92)$ & 0 by definition \\
Clinical carditis & $27(54)$ & \\
Subclinical carditis & $19(38) \ddagger$ &
\end{tabular}

*Influence on diagnosis to change to definite ARF in 2 (4\%).

tInfluence on diagnosis to change to definite ARF in $5(10 \%)$

flnfluence on diagnosis to change to definite ARF in $10(20 \%)$.

AHA, American Heart Association; ARF, acute rheumatic fever. subclinical carditis and monoarthritis) as opposed to $16 \%$ by Wilson et $a{ }^{13}{ }^{13}$ on usage of New Zealand guidelines when compared with the American Heart Association 1992 Jones update criteria. Thus, the newer guidelines have also resulted in increased yield of ARF, justifying the inclusion of these clinical features as major and minor manifestations for high-prevalence areas.

The sensitivity and specificity of any set of new criteria for ARF cannot be determined as there is no laboratory or objective test for ARF.

The Australian and AHA/ACC 2015 guidelines have the same set of major and minor manifestations in their Jones criteria for diagnosing recurrence activity but the standard defining norms for labelling recurrences are slightly different.

The definition logistics for recurrence activity in the AHA/ ACC 2015 and Australian guidelines are similar with respect to the need for two major criteria or three minor criteria towards the diagnosis. However, the differential requirement of one major and one minor criteria in Australian guidelines against one major and two minor criteria in AHA/ACC 2015 substantially increased the overall diagnostic yield with the Australian

\section{Key messages}

What is already known about this subject?

The Jones criteria are the standard for diagnosing acute rheumatic fever. It has undergone many revisions to improve its specificity based on the declining prevalence of the disease in the West. However, rheumatic fever is endemic in India, South East Asia and Africa. Hence, a single diagnostic criterion cannot be used worldwide. Keeping this in view the AHA/ACC has revised the Jones criteria in 2015 instituting modifications for the high-prevalence areas.

What does this study add?

The presentation of acute rheumatic fever (ARF) is different in our country from the West and other high-prevalence areas. Subclinical carditis and arthralgia were the predominant manifestations in our cohort. Applying the WHO 2004 guidelines led to underdiagnosis of disease in a significant proportion of cases. Inclusion of subclinical carditis, polyarthralgia and monoarthritis led to a greater detection rate of ARF and recurrence with the AHA/ACC 2015 and Australian guidelines. This is the first study to validate the use of the AHA/ ACC guidelines 2015 in a high-prevalence area like India.

How might this impact on clinical practice?

Rheumatic heart disease is a cause of significant morbidity and health expense in our country. Recurrences which lead to further cardiac damage can be prevented by secondary benzathine prophylaxis. Hence, it is very important to prevent misdiagnosis and underdiagnosis. The AHA/ACC 1992 WHO 2004 update, which is more appropriate for Western countries, leads to underdiagnosis of cases in our country. We found that newer guidelines which have incorporated subclinical carditis and broader definitions of arthritis as major criteria lead to a modest increase in cases of rheumatic fever. Nevertheless, the findings have implications for the management of definite cases of acute rheumatic fever in India who receive benzathine penicillin $\mathrm{G}$ secondary penicillin prophylaxis and for the probable or possible cases who were until now being denied prophylaxis in the absence of clear-cut guidelines. 
guidelines which is very well illustrated in our study. Of the 43 patients with suspected recurrence, only $67 \%$ fulfilled WHO 2004 and AHA/ACC 2015 while $88.4 \%$ patients had definite recurrence of rheumatic fever by Australian guidelines ( $\mathrm{p}$ value $0.01,95 \%$ CI 0.03 to 0.38 ).

A substantial number of patients in our study could not be classified as having first episode of ARF $(14 \%, n=7)$ or recurrence $(11.6 \%, \mathrm{n}=5)$ despite being highly suspected (in the absence of any other plausible diagnosis) to be, due to the absence of either essential criteria or one major or minor criteria. These patients have been addressed by the Australian guidelines as probable rheumatic fever and advised secondary penicillin prophylaxis. ACC/AHA 2015 has also created a niche 'possible rheumatic fever', and advised penicillin prophylaxis for those patients not fulfilling the Jones criteria on account of non-availability of laboratory tests for acute phase reactants or for confirmation of recent streptococcal infection, poor documentation of clinical features or unreliable history. ${ }^{1}$

Although the ACC/AHA 2015 revision has made the Jones criteria more sensitive for the Indian subcontinent, the diagnostic dilemma in some of our patients with first episode ARF and recurrence remains to be addressed. Australian guidelines have a better case definition rate vis-a-vis WHO 2004 both for first episode ARF and recurrence and also it makes a caveat for inclusion of probable case definitions which is very much needed in the Indian context. However, we could be overdiagnosing some of these cases but in a high-prevalence country like India overdiagnosis is better than underdiagnosis.

By subscribing to the still recent WHO 2004 criteria, 32\% of our suspected cases of ARF and 33\% of suspected recurrence cases would be refused treatment and prophylaxis, contributing significantly to the increase in the load of rheumatic valvular heart disease. However, the current revision of the Jones criteria respects the fact that there has to be a separate subset of recommendations to diagnose ARF in high-prevalence areas thereby addressing the issue of underdiagnosis and continued morbidity and mortality from chronic valvular heart disease.

Answers to the validity of the recently introduced guidelines can only be found through extensive studies on the high number of patients with rheumatic fever, which are hard to design in the developed countries due to the lower incidence of the disease. Experience and data from studies involving large series from low-income/middle-income countries shall provide answers in due course. The limitations of our study were the retrospective observational design and small sample size.

Acknowledgements We would like to thank Miss Reena Mehta for the technical support.

Contributors DK conceptualised the study and revised and approved the final manuscript. EB prepared and approved the manuscript. PK and BS collected and interpreted the data and searched the literature. AJ helped with statistical analysis. SC critically revised the manuscript for intellectual content.
Competing interests None declared.

Ethics approval Institutional Ethics Committee, Dr Ram Manohar Lohia Hospital.

Provenance and peer review Not commissioned; externally peer reviewed.

\section{REFERENCES}

1 Gewitz MH, Baltimore RS, Tani LY, et al. Revision of the Jones criteria for the diagnosis of acute rheumatic fever in the era of Doppler echocardiography. A scientific statement from the American Heart Association. Circulation 2015:131:1806-18.

2 RHD Australia (ARF/RHD Writing Group), National Heart Foundation of Australia, Cardiac Society of Australia and New Zealand. The Australian guideline for prevention, diagnosis, and management of acute rheumatic fever and rheumatic heart disease. 2nd edn. Casuarina, Australia: RHD Australia, 2012.

3 New Zealand Guidelines for Rheumatic fever 1. Diagnosis, management and secondary prevention. Heart Foundation of New Zealand, Cardiac Society of Australia and New Zealand, 2006. http://www.nhf.org.nz

4 Ozdemir 0 , Işık $S, A b a c ı$, et al. Silent enemy in acute rheumatic fever: subclinical carditis [in Turkish]. Turk Kardiyol Dern Ars 2011;39:41-6.

5 Cann MP, Sive AA, Norton RE, et al. Clinical presentation of rheumatic fever in an endemic area. Arch Dis Child 2010;95:455-7.

6 Beg A, Sadiq M. Subclinical valvulitis in children with acute rheumatic fever. Pediatr Cardiol 2008;29:619-23

7 Carapetis JR, Currie BJ. Rheumatic fever in a high incidence population: the importance of monoarthritis and low grade fever. Arch Dis Child 2001;85:223-7

8 Dajani AS, Ayoub E, Bierman FZ, et al. Special Writing Group of the Committee on Rheumatic Fever, Endocarditis, and Kawasaki Disease of the Council on Cardiovascular Disease in the Young of the American Heart Association. Guidelines for the diagnosis of rheumatic fever: Jones criteria, 1992 update. JAMA 1992;268:2069-73.

9 World Health Organization. Rheumatic fever and rheumatic heart disease. Technical report. 2004:923. http://www.ncbi.nlm.nih.gov/entrez/query.fcgi? $\mathrm{cmd}=$ Retrieve \&db=PubMed\&dopt=Citation\&list_uids $=15382606$

10 Sanyal SK, Berry AM, Duggal S, et al. Sequelae of the initial attack of acute rheumatic fever in children from north India. A prospective 5-year follow-up study. Circulation 1982:65:375-9.

11 Agarwal BL, Agrawal R. Rheumatic fever. Clinical profile of the initial attack in India. Bull World Health Organ 1986;64:573-8.

12 Danchin MH, Carlin JB, Devenish W, et al. New normal ranges of antistreptolysin 0 and antideoxyribonuclease B titres for Australian children. J Paediatr Child Health 2005:41:583-6.

13 Wilson NJ, Voss L, Morreau J, et al. New Zealand guidelines for the diagnosis of acute rheumatic fever: small increase in the incidence of definite cases compared to the American Heart Association Jones criteria. N Z Med J 2013;126:50-9.

14 Saxena A, Ramakrishnan S, Roy A, et al. Prevalence and outcome of subclinical rheumatic heart disease in India: the rheumatic (Rheumatic heart echo utilisation and monitoring actuarial trends in Indian children) study. Heart 2011:97:2018-22

15 Padmawati S, Arora R. Profile of rheumatic fever and rheumatic heart disease in India. In: Ahuja MMS, ed. Progress in clinical medicine in India. 2nd series. New Delhi: Arnold Heinemann 1978:219.

16 Roy SB. The diagnosis of rheumatic fever. J Indian Med Assoc 1960;35:344-6.

17 Rayamajhi A, Sharma D, Shakya U. Clinical, laboratory and echocardiographic profile of acute rheumatic fever in Nepali children. Ann Trop Paediatr 2007:27:169-77.

18 Kaplan EL, Anthony BF, Chapman SS, et al. The influence of site of infection on the immune response to group A streptococci. J Clin Invest 1970;49:1405-14.

19 Carapetis JR, Currie BJ. Group A streptococcus, pyoderma, and rheumatic fever. Lancet 1996:347:1271-2. 